\title{
THE VISUAL FIELD DEFECTS IN SUBACUTE COMBINED DEGENERATION OF THE SPINAL CORD
}

\author{
BY \\ G. H. H. BENHAM \\ From the Department of Neurology, Manchester Royal Infirmary
}

The occurrence of optic atrophy as part of the syndrome of subacute combined degeneration of the spinal cord is distinctly uncommon (Woltmann, 1919 ; Smithburn and Zerfas, 1931 ; Young, 1932). A clinical review and resumé of the literature was given by Turner (1940), who reported three cases and was the first writer to comment specifically on the characteristics of the visual field defects. The purpose of this communication is to record further observations on the fields of vision in this syndrome, and to discuss their possible significance and clinical importance.

\section{Review of the Literature}

In only a few instances have the visual fields been described. Bickel's (1914) patient had a central scotoma in the left eye, and the case is quoted by Turner (1940) as a possible example of the condition. But the post-mortem findings comprised marked perivascular cellular infiltration in posterior and lateral columns, with proliferation of the vessels themselves, and it seems impossible to accept the case as one of subacute combined degeneration. Hine (1936) reported full peripheral fields with a central colour scotoma in each eye, most marked for green and very difficult to chart accurately, in his patient, whereas Talbot (1936) recorded full fields for $1^{\circ}$ white, but noted a large relative central scotoma in each eye. Neither of these authors published charts, nor did they allude in the text to the distinction between the pericentral and centrocaecal types of scotoma. Box (1936) reported " left field full " in his patient, but the acuity in this eye was as good as $6 / 12$ after correction and it is not stated that a specific search was made for a scotoma. Cohen (1936) described slight concentric contraction only in his two patients, but the gross reduction in visual acuity to $6 / 60,6 / 36$ and $6 / 60,6 / 60$ seems inconsistent with this finding unless the central fields were also involved by scotomata. Kampmeier and Jones (1938) mention the fields only in their second patient, saying that there was no apparent gross defect; despite this the acuity was very seriously reduced, and they indicate that the subject was somewhat uncooperative. Courville and Nielsen (1938) report that their second patient had marked constriction of the visual fields, and though they note that the Bjerrum screen was used they do not say whether the presence of scotoma was excluded. Turner (1940) published charts from two of his three cases, all of which presented essentially centrocaecal defects barely covering the fixation point, or even falling short of it ; there was slight or moderate peripheral constriction. Traquair (1946) pictures charts of almost identical appearance from a case which, though clinical details are not given, is described as "retrobulbar neuritis in pernicious anaemia with subacute combined degeneration of the spinal cord ". In the text on another page, however, he says that the visual fields in pernicious anaemia are similar to those of Leber's disease - with a dense scotoma freely involving the fixation area, possibly fibre bundle defects, and frequent affection of the peripheral field-and do not present any distinguishing features. Walsh (1947) in his textbook mentions a case of pernicious anaemia showing bilateral field defects like those described by Turner (1940), but does not detail the signs and symptoms.

To sum up, the peripheral fields in these recorded cases are usually full or nearly so and only exceptionally do they show marked contraction. Really adequate data about the central fields are available only in the cases of Turner (1940) and Traquair (1946), all four showing a centrocaecal pattern, but Traquair gives no clinical details to permit certain identification of his case as one of subacute combined degeneration. A fifth case (Walsh, 1947) is probably identical, but categorical information is lacking both as to ocular and general clinical findings.

\section{Clinical Observations}

During the examination of a series of 112 treated and untreated cases of subacute combined degeneration of the spinal cord five instances of optic 
atrophy were encountered. Two of the five patients were unable to cooperate satisfactorily in examination of the visual fields, one on account of dementia occurring as part of the neurological syndrome and the other on account of the onset of senile deterioration. The remaining three cases are described below.

\section{Case Reports}

Case 1.-A woman aged 59 was admitted to hospital in 1941 with a history of general weakness for six months and of weakness of the hands and difficulty in walking for two weeks. While in the ward she became aware for the first time of impairment of vision. She had incomplete pyramidal and posterior column signs, achlorhydria, and a red-cell count of $1,630,000$ per about $3^{\circ}$. The intrinsic muscles of both hands were a little weak and the power of opposition of the little fingers was lost. Tone was a little increased in both lower extremities. The tendon reflexes, with the exception of the ankle jerks, were much exaggerated, and sustained patellar clonus was present. The right plantar response was extensor and the left unobtainable, whilst the abdominal reflexes were absent. Two-point discrimination was impaired in the fingers of both hands, and vibration sense lost below the level of the iliac crests ; sensation was normal in other modalities. The gait appeared normal. The other systems were normal and the blood pressure 190/100, without evidence of peripheral arteriosclerosis. A blood count showed red cells $4,930,000$ per c.mm., haemoglobin $98 \%$, and white cells 5,200 per c.mm.

The clinical features of this case, and its response to treatment, justified a diagnosis of pernicious anaemia with subacute combined system disease. Visual failure developed during the course of the illness and may fairly be considered an integral part.

Case 2.-A man aged 68 was admitted to hospital with a history of unsteadiness in walking for two years and of gradual visual failure, tingling in the finger tips, and nocturnal cramps in the feet, for one year. He smoked one ounce of mild tobacco weekly.

The visual acuity was ${ }^{3} / 60$ in each eye, and both optic discs $=3 / 60$, L.V. $=6 / 36$. Objects $10 / 2000,{ }^{3} / 2000$ white, ${ }^{15} / 2000$ red; blind spot ${ }^{40} / 2000$ white.

c.mm. with haemoglobin $42 \%$, colour index 1.31 , and white cells 5,000 per c.mm. The reticulocyte count was $8.8 \%$, and many nucleated red cells were present in the peripheral blood. There was a rapid response to parenteral liver therapy, which was continued indefinitely.

When I first saw the patient in 1948 she reported slight numbness and clumsiness of the hands, preventing the use of a sewing needle, and considerable impairment of vision, so that small print could not be distinguished and the recognition of faces at a distance was difficult. On examination the visual acuity was ${ }^{3} / 60$ right, $6 / 36$ left and both optic discs showed marked pallor, maximal in the temporal halves. The visual fields (Fig. 1) showed considerable concentric contraction, greater in the right eye, and large dense scotomata of centrocaecal type with steep edges just overlapping the fixation point ; on perimetry, fixation in each eye was eccentric by

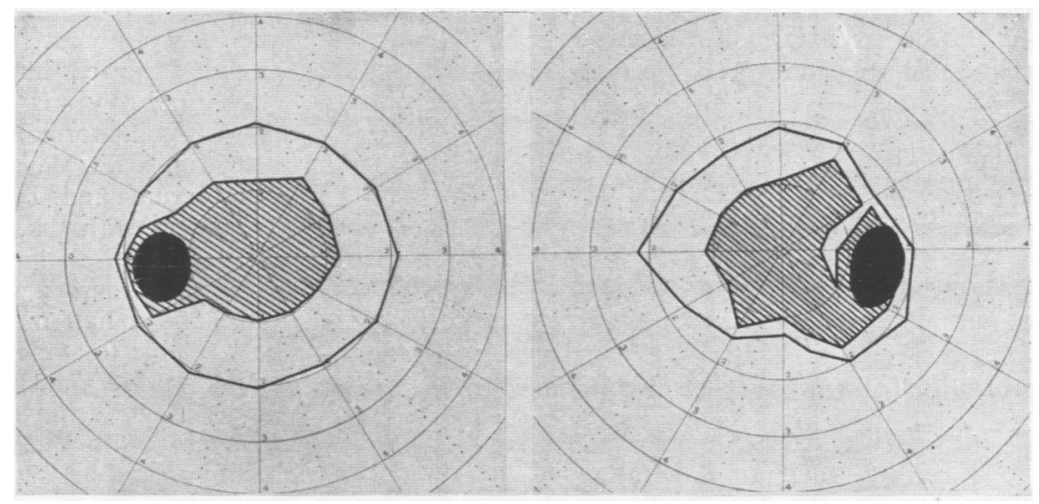

Fig. 2.-Visual fields in Case 2 before treatment. R.V. and L.V. $=3 / 60$. Object ${ }^{5} / 2000$ white; blind spot ${ }^{15} / 2000$ white. showed marked pallor. The visual fields (Fig. 2) showed considerable concentric contraction and very large pericentral scotomata extending temporally to include the blind-spots. Both legs were grossly ataxic, and the sense of passive movement was impaired in all 


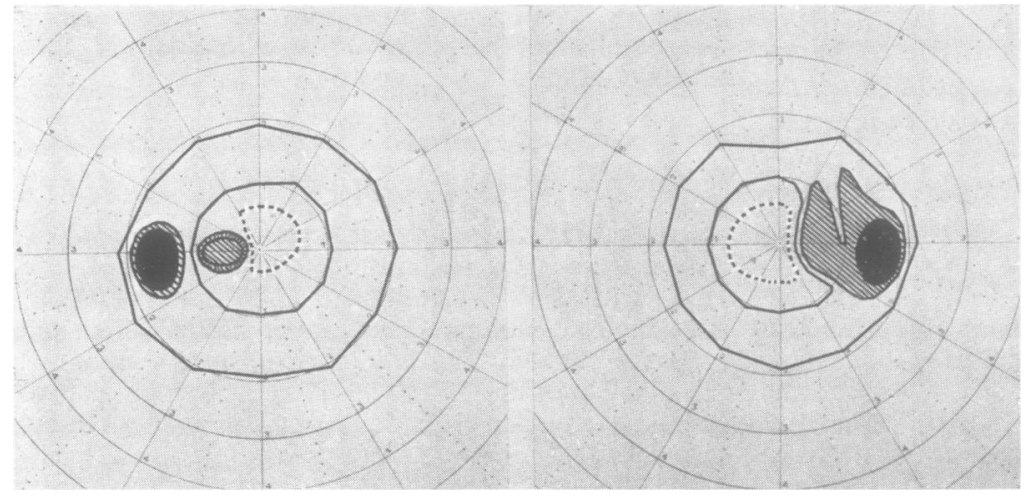

Fig. 3.-Visual fields in Case 2 after treatment. R.V. and L.V. $=6 / 18$. Objects $5 / 2000,2 / 2000$ white, $10 / 2000$ red; blind spot ${ }^{40} / 2000$ white.

progressive visual failure for nine months ; unsteadiness of gait for eight months ; and an abdominal girdle sensation for one month. Ten years before he had had thyrotoxicosis but recovered following operative treatment. $\mathrm{He}$ had been in the habit of smoking four ounces of twist weekly, but had ceased to do so six months before examination.

He had obvious exophthalmos and a red glazed tongue. The visual acuity was ${ }^{6} / 60$ right, $6 / 36$ left; the right optic disc showed temporal pallor and the left general pallor. The legs were ataxic, with impairment of the sense of passive movement and of vibration sense, but super-

the toes; vibration sense was lost only in the right foot. The knee and ankle jerks were absent, but the plantar responses were flexor and the abdominal reflexes intact. The gait was grossly ataxic with a broad base, and Romberg's sign was positive. Arcus senilis was prominent, but the other systems were normal and the blood pressure only $145 / 100$, with no significant peripheral arterial thickening. The cerebrospinal fluid was normal and the Wassermann reaction negative. A blood count showed red cells $2,840,000$ per c.mm., haemoglobin $58 \%$, colour index 0.98 , and white cells 2,050 per c.mm. The sternal marrow was normoblastic, but it was discovered that liver extract had been given just before the patient's admission to hospital. A histamine-fast achlorhydria was demonstrated.

Intensive liver therapy was given, and two and a half months later the patient's paraesthesiae had almost disappeared, he was walking much better, and vision had greatly improved. The acuity was now $6 / 18$ in each eye and the fields (Fig. 3), though still showing marked concentric contraction, displayed great diminution in the size of the scotomata, which were now essentially centrocaecal in pattern, just falling short of the fixation points. The red cell count had risen to $4,520,000$ per c.mm., with haemoglobin $90 \%$ and white cells 5,000 per c.mm.

Pyramidal signs were lacking and posterior column signs incomplete, but the neurological picture was consistent with the earlier phases of subacute combined degeneration, and this diagnosis was supported by haematological findings and the response to specific therapy. Visual failure presented as an integral part of the illness and likewise improved remarkably with treatment; the consumption of tobacco was insufficient to have any bearing on the amblyopia.

Case 3.-A man aged 47 attended the out-patient clinic complaining of tingling sensations of one year's duration, involving first the fingers and toes and later spreading up the legs and trunk to the waist level; ficial sensibility appeared intact and no muscle tenderness was present. The reflexes were normal apart from exaggeration of the knee and ankle jerks. The other systems were normal and the blood pressure was $130 / 80$. The red cells numbered $4,620,000$ per c.mm., with haemoglobin $92 \%$, and white cells 7,600 per c.mm.

One month later the patient began to deteriorate rapidly, developing retention of urine and complete inability to walk. He was admitted to hospital, where he was found to have low-grade fever, considerable oedema of both legs, profound weakness and ataxia of the legs, exaggerated tendon reflexes and extensor plantar responses with absent abdominal reflexes, absent vibration sense throughout the lower extremities, and loss of the sense of passive movement in toes, ankles, and knees. The cerebrospinal fluid was normal andēe the Wassermann reaction negative. A blood count showed red cells $3,460,000$ per c.mm., haemoglobin $68 \%$, colour index 0.98 , and white cells 4,900 per c.mm. with normal differential count. The absolute red cell indices were all within normal limits. There was a reticulocytosis which persisted throughout the illness at a level of $3 \%$ to $4 \%$, but the serum bilirubin and saline fragility were within normal limits and occult blood was always absent from the stools. Fractional gastric analysis showed histamine-fast achlorhydria, but the sternal marrow was normoblastic. Liver function tests showed no abnormality.

Within a few days he developed pressure sores over the sacrum and buttocks and a urinary infection. Treatment with "hepastab", $4 \mathrm{ml}$. daily, was begun, and within a week the paraesthesiae had become much less marked. Progress was otherwise very slow, but after three and a half months all bedsores had healed and he was able to stand though not to walk; the red cell count was 4,530,000 per c.mm., and the haemoglobin $86 \%$. After a further three months he could walk 200 yards with the aid of a stick. The visual acuity had improved to ${ }^{6} / 36$ right, ${ }^{6} / 18$ partly left ; the visual fields (Fig. 4) showed bilateral centrocaecal scotomata with a slight col between fixation point and blind spot, whilst their peripheral extent was nearly full. 


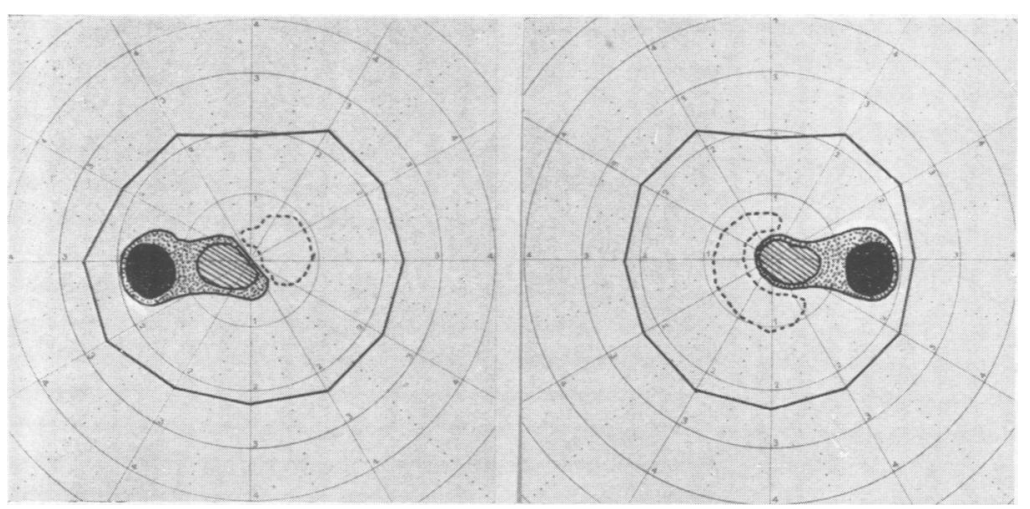

FIG. 4.-Visual fields in Case 3. R.V. $=6 / 36$, L.V. $=6 / 18$ pt. Objects ${ }^{2} / 2000$ white, $10 / 2000$ red; nucleus $10 / 2000$ white; blind spot $10 / 2000$ white.

The gait continued steadily to improve and the red cell count reached $5,280,000$ per c.mm. with a haemoglobin of $102 \%$, but the visual acuity and visual fields displayed no further change.

This man had a normocytic anaemia with a persistent reticulocytosis of 3 to $4 \%$, and the case did not show the haematological features of pernicious anaemia. Neurologically, however, the illness presented with obtrusive, slowly spreading paraesthesiae in all four limbs, followed by ataxic paraplegia with posterior column signs antedating pyramidal signs. This picture, associated with glossitis and histamine-fast achlorhydria, would seem to justify a diagnosis of subacute combined degeneration of the cord, and this is further supported by the response to liver therapy: slow but uninterrupted recovery followed the beginning of this treatment, whereas before its institution the symptoms were steadily aggravated without remission. The phase of rapid deterioration just before admission to hospital, with crural paralysis, sphincter disturbances, fever and oedema of the lower half of the body, is reminiscent of the classical description by Russell, Batten, and Collier (1900). The possibility that tobacco was the cause of the amblyopia had to be considered, as the patient had been a heavy smoker of twist, but cessation of the habit for six months had brought about no improvement in vision, and the onset of the paraesthesiae of the extremities three months before the beginning of visual failure strongly suggests that the latter symptom was in fact part of the major neurological disorder. Moreover vision improved pari passu with the other neurological functions when liver therapy was given.

\section{Discussion}

The Type of Field Defect.-The peripheral fields in these patients showed great variation, ranging from almost full extent in Case 3 to severe contraction in Case 2.

Only in Case 2 was an opportunity afforded to examine the central fields before treatment, and here the pattern was one of pericentral scotoma of about $10^{\circ}$ radius linked to the enlarged blind spot by a rather narrower zone. Fixation and cooperation tended to be imperfect at this stage of the illness, and exhaustive examination using many different visual angles was precluded by fatigue. The central fields after treatment presented features of similarity in each of the three cases (Figs. 1, 3, and 4). The scotomata were bilateral and centrocaecal in position, with the nasal edge quite close to the fixation point. The vertical extent was variable, but the long axis was always horizontal, and in two instances (Cases 2 and 3) there was narrowing and diminished density to the nasal side of the blind spot. The scotomata were dense, with steep edges, and disproportion for colour was not present-findings consistent with the stationary condition of the lesion at the time of examination.

The close resemblance of the centrocaecal defects in these three cases to those found in the more fully reported cases in the literature is evident. The material is still limited to eight cases in all, and further observations are necessary, but it is of interest to examine the question of whether there is any special significance in this frequently occurring centrocaecal pattern.

Significance of the Centrocaecal Scotoma.According to Lillie (1934) this scotoma has no real individuality, being merely a stage in the progress of the symptoms of an optic nerve lesion, of any aetiology, from an initial pericentral scotoma to ultimate blindness. But though this sequence may occur in some instances, there are many obvious exceptions; thus in tobacco amblyopia a symmetrical pericentral scotoma does not occur and the major defect throughout the illness lies between blind spot and fixation point. It is true that the centrocaecal scotoma has been reported in many conditions which have little in common with one another, including acute retrobulbar neuritis, Leber's disease, diabetes, syphilis, arteriosclerosis, and pressure lesions (Duke-Elder, 1940 ; Traquair, 1946). But, as noted by Traquair (1923), it is relatively infrequent in disseminated sclerosis and in Leber's disease, whereas it is the rule in tobacco 
amblyopia, and it seems hardly possible to doubt that it is an entity with some specific mechanism of origin.

No pathological studies appear to have been made in cases of amblyopia associated with subacute combined degeneration, and ideas as to the mechanism of production of the changes in the visual fields can therefore be only theoretical and speculative. But in tobacco amblyopia many observations have been made on the morbid anatomy (Parsons, 1908 ; Duke-Elder, 1940) and there is general agreement that there is degeneration both of the papillo-macular bundle and also of retinal ganglion cells, but which of these sites represents the primary lesion remains unsettled. It is not easy fully to correlate this pathological incrimination of the papillo-macular fibres with the anatomical features of the scotoma. The papillo-macular bundle innervates the foveal area of the retina, and damage to the bundle might be expected to produce a symmetrical pericentral scotoma of about $5^{\circ}$ radius, which in fact occurs with many optic nerve lesions. Two deductions then seem reasonable concerning the centrocaecal type of scotoma. First, involvement of macular fibres must be very unequal and asymmetrical. Second, that part of the scotoma between the $5^{\circ}$ and $13^{\circ}$ circles must be due to damage to extramacular fibres. As the retinal area in question is nasal to the macula these fibres must be crossed fibres situated in the nasal half of the optic nerve. The exact site of such juxtapapillary fibres in the optic nerve is still disputed, but whether it be axial or peripheral it is very difficult to conceive of a unitary lesion within the nerve which could account on any known anatomical basis for simultaneous damage to papillo-macular fibres and to this curiously selected group of nasal extramacular fibres. Anatomical considerations in fact seem strongly to favour a primary disturbance in the retina, where the affected neural elements are disposed in contiguity.

A primary retinal lesion was proposed by Parsons (1908), who suggested, as possible mechanisms, poisoning of synapses between retinal elements and retinal vascular spasm; but the selective vulnerability of particular neurons remained unexplained. Behr (1935) on the contrary, insisted that the lesion was primary in the nerve, quoting pathological observations that the severity and extent of damage to the papillo-macular bundle was inversely correlated with the richness of its blood supply and was histologically maximal in the intracranial portion of the nerve, but correlation with the clinical features of the scotoma-referred to as "central "-was not attempted. Traquair (1923) thought that a specific anatomical site for the lesion could not be assigned, and believed that certain nerve elements might have a special affinity for the toxic substances : later (Traquair, 1946) he added that the pronounced tendency of the scotoma to lie along the horizontal meridian was suggestive of a nutritional and ultimately anatomical basis for the special susceptibility.

A new approach to the problem of a retinal basis for this scotoma has been made by Evans (1940). He claims that in some circumstances the centrocaecal scotoma may undergo transient fluctuation in size pari passu with variation in the angioscotoma of the main retinal vessels, and he argues that a vascular origin for this field defect is thereby demonstrated. The retinal area concerned is largely supplied by the cilio-retinal system, whether or not frank cilio-retinal arteries are visible with the ophthalmoscope : these vessels must then supply the macular fibres as they traverse the retina, though not the fovea itself which is avascular and nourished from the choroidal blood bed. A primary foveal lesion is therefore unlikely from vascular causes, but if a toxic or degenerative lesion of the macular fibres occurs, Evans (1940) suggests that " there may be a call for greater metabolic activity of ... paramacular vessels as a gesture towards the restoration of local function", and that such " derangements of this minute vascular tree doubtless cause interruptions in the passage of the nerve impulse from the cells in the region it supplies", thus producing the centrocaecal field defect.

This hypothesis at once permits interpretation of the conditions found in Case 2 reported in this paper. The severe concentric contraction and the large pericentral scotoma alike suggest neuronal damage of exceptional degree. This may be supposed to call forth a response by the paramacular vessels which, though maximal, is unable to restore normal macular function. After treatment it may be presumed that the vascular response is adequate to restore function in the now less severely damaged central fibres, and thus the pericentral scotoma disappears, but the centrocaecal scotoma resulting from the vascular derangement persists, though reduced in extent. But although this theory of Evans (1940) is thus helpful, and in many other ways attractive, it is still open to criticism. It does not account for the temporal field defects sometimes observed for small visual angles between the $20^{\circ}$ and $30^{\circ}$ circles (Traquair, 1946). It does not explain the nature of the metabolic mechanism supposed to call forth the vascular response, nor the restriction of the phenomena to certain groups of cases with papillo-macular damage. There is also a possible non sequitur in that the vascular changes are presumed simultaneously responsible for restoration 
of function in the macular fibres and for impairment of function in the ganglion cells and synapses in the same retinal area. However, till more detail is forthcoming than is available in the originator's brief formulation quoted above, a just assessment will not be possible.

If this hypothesis, of a dual origin, neural and vascular, for the centrocaecal scotoma, be tentatively accepted, has the occurrence of the latter in cases of subacute combined degeneration any special significance? The idea has indeed long been current that a vascular factor might explain the characteristic distribution of the lesions of subacute combined degeneration within the nervous system (Russell, Batten, and Collier, 1900 ; Wilson, 1940 ; Biggart, 1949) but a satisfactory precise formulation has never been achieved. Stannus (1944) claimed that in ariboflavinosis the lesions were situated in those parts of the nervous system with the richest capillary blood supply, and advanced the concept of a " capillary dysergia " manifesting itself by dilatation of vessels and retardation of flow, causing interference with normal cellular metabolism and derangement of tissue function. The tentative description given by Evans (1940) of dilatation of the paramacular vessels is reminiscent of this hypothesis, but the two theories differ fundamentally: with Stannus (1944) the vessels dilate because of intrinsic capillary damage of nutritional origin, whereas with Evans (1940) they dilate in response to some change in the tissues they supply. Moreover, the concepts of Stannus (1944), whatever their relevance to ariboflavinosis, cannot well explain the distribution of lesions in subacute combined degeneration, in which areas of low vascularity like the posterior columns (Stannus, 1944) are commonly involved. Neither is the problem clarified by direct comparison of the visual field changes in subacute combined degeneration with those in other forms of nutritional neuropathy. The centrocaecal form is uniform in tobacco amblyopia, which many workers consider of nutritional origin (Carroll, 1936), whilst conflicting findings are reported in the amblyopias sometimes associated with diabetes and chronic alcoholism (Duke-Elder, 1940 ; Traquair, 1946). In the nutritional neuropathies occurring in prisoners of war Spillane's (1947) cases presented the pericentral type of scotoma, though some were so large as to engulf the blind spot, while Graveson (1947) reported nearly $15 \%$ incidence of centrocaecal defects, $65 \%$ being pericentral and the remainder paracentral or annular.

The problem therefore is very far from solution. It can only be said that a retinal vascular factor as well as a neural factor seems probable in the genesis of the centrocaecal scotoma. In the ambly- opia of subacute combined degeneration it is tempting to try to relate such a vascular factor to vascular theories of the genesis of the disease, but evidence on the question is conflicting and uninformative.

The Field Changes and Differential Diagnosis.The observations recorded in this paper have considerable clinical importance in relation to the problem of diagnosis and treatment of the middleaged patient presenting with subacute onset of bilateral amblyopia with centrocaecal scotoma. In my experience the commonest conditions with this clinical picture are tobacco amblyopia and a socalled chronic retrobulbar neuritis; but the possibility of subacute combined degeneration must be considered in every such case, and this is of great importance because of the chance of amelioration or cure by specific therapy, which is more effective neurologically the earlier it is applied.

The majority of cases of subacute combined degeneration can be recognized by the presence of other abnormal neurological signs. Nevertheless optic atrophy from this cause may occur before the development of signs elsewhere in the nervous system (Turner, 1940), or even before blood changes become manifest (Cohen, 1936), and in such cases diagnosis may be very difficult. Achlorhydria is a sine qua non, but occurs in a considerable proportion of elderly subjects without pernicious anaemia (Oliver and Wilkinson, 1933), and such points as soreness of the tongue and a family history of pernicious anaemia may assume considerable importance. If all these fail a controlled therapeutic test with liver extract may be justifiable.

Writers on tobacco amblyopia have tended perhaps to oversimplify the diagnosis. Thus Traquair $(1930,1946)$ emphasizes the importance of other diseases in precipitating the onset of amblyopia, and Carroll (1935) refers to a case associated with pernicious anaemia. Whether or not such patients make full visual recovery, it seems to me difficult to be sure that the essential factor was not pernicious anaemia rather than tobacco ; this problem arose in Case 3 of the present series. Secondly Traquair $(1930,1946)$ claims that the special characters of the visual fields in tobacco amblyopia are virtually pathognomonic. But these characters, which include diffuseness of the scotoma with sloping edges and marked disproportion for colours, are merely expressive of a diffuse lesion producing partial impairment of function of many nerve elements, but destroying only a few. Now many cases of subacute combined degeneration show very slow progression of spinal signs and symptoms, and if the ocular lesions advance at a similar rate 
it is clearly not impossible that a case in the early stages of amblyopia might present signs of partial impairment of retinal function similar to those of tobacco amblyopia. The description of Hine (1936), quoted earlier in this paper, is illustrative of this point, even though he does not detail the exact location of the scotoma.

"Chronic retrobulbar neuritis" is not a very well defined entity. One group of cases is alluded to by Duke-Elder (1940), who emphasizes the resemblances to the toxic amblyopias rather than to the inflammatory lesions, the frequent bilateral involvement, the slow onset, chronicity, and poor prognosis. Traquair (1930) also describes similar cases presenting centrocaecal scotomata, and during the period in which the cases of subacute combined degeneration here reported were collected I have seen four cases approximating to this clinical picture. There was no indication of the aetiology. All were over 50 and the age incidence is not dissimilar to that of pernicious anaemia. Where free acid is present in the gastric juice, diagnosis is less difficult, but if there is achlorhydria, a controlled therapeutic trial with liver extract may be desirable.

\section{Summary}

The literature of optic atrophy associated with subacute combined degeneration of the spinal cord is reviewed with reference to the changes reported in the fields of vision.

In a group of 112 cases of subacute combined degeneration five instances of optic atrophy were encountered ; in three of these accurate assessment of the visual fields was possible, the essential defects being scotomata of centrocaecal type with varying degrees of peripheral contraction.

The significance of these observations is discussed and the diagnostic importance noted.

I wish to thank Dr. F. R. Ferguson and Dr. J. F. Wilkinson for permission to quote cases under their care in the Departments of Neurology and Haematology at the Manchester Royal Infirmary.

\section{REFERENCES}

Behr, C. (1935). v. Graefes Arch. Ophthal., 134, 227.

Bickel, H. (1914). Arch, Psychiat. Nervenkr., 53, 1106.

Biggart, J. H. (1949). "Pathology of the Nervous System ", 2nd ed. Edinburgh.

Box, C. R. (1936). Lancet, 2, 1269.

Carroll, F. D. (1935). Arch. Ophthal., Chicago, 14, 421. (1936). Ibid., 16, 919.

Cohen, H. (1936). Lancet, 2, 1202.

Courville, C. B., and Nielsen, J. M. (1938). Bull. Los Angeles neurol. Soc., 3, 83.

Duke-Elder, W. S. (1940). "Text-book of Ophthalmology." Vol. 3. London.

Evans, J. N. (1940). Arch. Ophthal., Chicago, 24, 532.

Graveson, G. S. (1947). M.D. thesis. University of Cambridge.

Hine, M. L. (1936). Proc. R. Soc. Med., 29, 386.

Kampmeier, R. H., and Jones, E. (1938). Amer. J. med. Sci., 195, 633.

Lillie, W. I. (1934). Amer. J. Ophthal., 17, 110.

Oliver, T. H., and Wilkinson, J. F. (1933). Quart. J. Med. 26, 431.

Parsons, J. H. (1908). "The Pathology of the Eye." Vol. 4. London.

Russell, J. S. R., Batten, F. E., and Collier, J. (1900). Brain, 23, 39.

Smithburn, K. C., and Zerfas, L. G. (1931). Arch. Neurol. Psychiat., Chicago, 25, 1100.

Spillane, J. D. (1947). "Nutritional Disorders of the Nervous System." Edinburgh.

Stannus, H. S. (1944). Brit. med. J., 2, 103 and 140.

Talbot, G. (1936). Brit. J. Ophthal., 20, 619.

Traquair, H. M. (1923). Trans. ophthal. Soc. U.K., $43,480$.

-(1930). Ibid., 50, 351.

(1946). "An Introduction to Clinical Perimetry." 5 th ed. London.

Turner, J. W. A. (1940). Brain, 63, 225.

Walsh, F. B. (1947). "Clinical Neuro-Ophthalmology." Baltimore.

Wilson, S. A. K. (1940). “Neurology." Vol. 2. London.

Woltmann, H. W. (1919). Amer. J. med. Sci., 157, 400. Young, R. H. (1932). J. Amer. med. Ass., 99, 612.

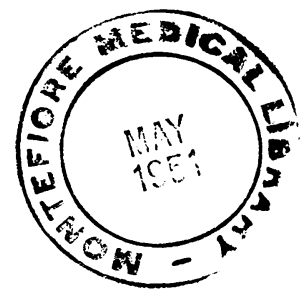

